\title{
Obituary
}

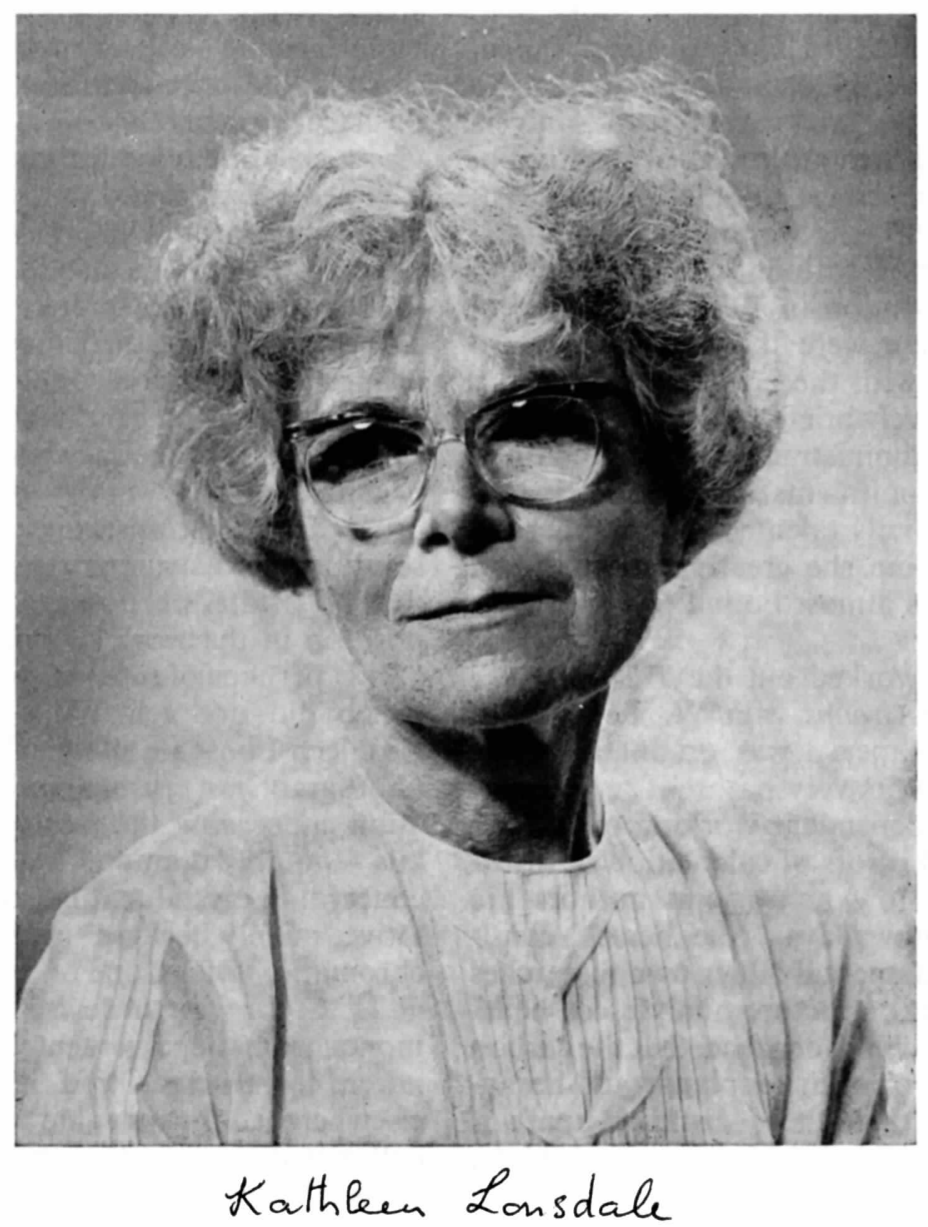

\section{Kathleen Lonsdale \\ 28 January 1903 - 1 April 1971}

No group of scientists can have documented itself more comprehensively than the crystallographers represented in Fifty years of X-ray Diffraction, a fact which makes it rather difficult to write a short memoir of one of their number. Since this tribute will appear contemporaneously with the admirable Obituary Notice prepared by Professor Dorothy Hodgkin for the Royal Society a Notice which contains a full account of Kathleen Lonsdale's early life and a complete bibliography of her scientific publications, I have concentrated on that part of her career with which she herself did not deal in her Reminiscences (Fifty years, pp. 595-602), and of which I have first-hand knowledge - namely the period from 1946 until she retired in 1968 as Professor of Chemistry and Head of the Department of Crystallography in University College London.

The pattern of her life did in fact alter quite significantly at about the time that W. H. Bragg died, and for reasons that were not wholly scientific. It was then that she began to have a public as well as a private life. She first attracted public attention by spending a month in Holloway Gaol (1943) for refusing to register for fire-watching (an activity from which as the mother of young children she was in any case exempt, and in which she was in fact aotually participating) as a matter of conscience. She ultimately derived a good deal of benefit from this undeniably unpleasant experience, both in the broadening of her own attitude towards others, and in the opportunity which it gave her to work for the improvement of our prison system in various capacities later on. She had by this time also made notable contributions to the study of crystals, particularly in respect of thermal vibrations in a variety of substances, and was soon in the public eye again (in 1945) as one of the first two women to be elected to the Fellowship of the Royal Society - an honour which gave her particular pleasure. From then on her scientific activities and her social and religious concerns became closely interwoven, and she seldom thereafter undertook a journey for one purpose without managing also to further the other. 
Born in Ireland at Newbridge, County Kildare on 28 January 1903, the tenth and youngest child of an English postmaster, Kathleen Yardley took high honours in physics at Bedford College for Women, University of London, in 1922, and was invited by W. H. Bragg to join his research team, first at University College London and then at the Royal Institution. For two years after her marriage to a fellow physicist, Thomas Lonsdale, in 1927, she worked at the University of Leeds, but returned with him to London and rejoined the Royal Institution in 1932, where she remained until 1946. These were the halcyon days to which she looked back with the greatest pleasure - a period, apart from relatively brief interruptions, of fulltime research free from administrative worries and timeconsuming outside commitments, carried on in the company of an exceptionally talented group under the leadership of a man whom she greatly admired. Any subsequent situation was almost bound to be an anticlimax.

During this time she worked out the Tables for the Determination of Space Groups with W. T. Astbury, who wrote later 'The paper...was originally begun by Miss Yardley, but by its very nature it required at least a duplicate but independent working out of the results in order to avoid errors of calculation or drawing...' (One wonders how many joint authors are equally conscientious nowadays). She herself considered that the most fundamental of her own researches was the proof, by crystal structure analyses of hexamethylbenzene and hexachlorobenzene, that the carbon atoms in the benzene nucleus are coplanar and hexagonally arranged, and that their distance apart is nearly the same as that of the carbon atoms in graphite. Later by measuring the diamagnetic susceptibilities in and perpendicular to the planes of a number of aromatic molecules, she was able to show the reality of the concept of molecular orbitals. For this and later work she was awarded the Davy Medal of the Royal Society in 1957.

It was, however, her work on crystal dynamics which provided the mainspring of her research interests after she returned to University College in 1946. While at the Royal Institution, she had shown by studies of well-exposed Laue photographs of simple substances three things: firstly that the diffuse scattering of long wavelength was directly related to the elastic constants of the crystal; secondly that the diffuse pattern was very dependent upon the crystal structure, and could be used to determine molecular orientation, and thirdly that the finer details of the structures of organic compounds could be related to the strengths of intermolecular bonds. She also showed that some effects, particularly the 'extra spots' in Type I diamonds, were structure- and not temperature-sensitive, and must be due to disorder and not to thermal vibration. It was largely for these researches that she was elected to the Royal Society in 1945, but she was aware that they did not belong to the mainstream of structural research.
In her account of $X$-ray Diffraction and its Impact on Physics (Fifty years, pp. 221-247) she writes: 'nowadays X-ray crystallographers, particularly if their basic training is in chemistry, study the dynamics of crystals; but only because they must. In order to refine the structure of an organic compound to the point where accurate bond lengths and angles are obtainable it is necessary to find and to make allowance for the anisotropic atomic thermal vibrations. To the early research workers, as also to the crystallographer-physicist of today, the interest is in the dynamics itself, and in its relation to a host of independent physical properties'. She goes on to mention melting, elastic constants, specific heat, zero-point energy and thermal expansion. The major extension of that interest which began about 1962 was the study of solid-state reactions, order-disorder transitions, short-range order in solid solutions, and structural aspects of photo-reactions in the solid state, phenomena which still occupy a main position in the work of this laboratory.

It is perhaps of interest to recall some of the projects which did not gel. While at the Royal Institution Kathleen Lonsdale showed how divergent-beam X-ray photography of crystals could yield very precise information concerning the lattice parameters of cubic crystals - notably diamond - as well as some information concerning crystal texture, though this was only qualitative, mainly because the X-ray beam was not monochromatic. In fact, one of my first activities on arriving at U. C. L. was to devise a method for producing a monochromatic divergent beam, but the device was never constructed, and textural studies developed elsewhere via topographic methods involving very well collimated beams rather than divergent ones. Kathleen Lonsdale never returned to textural studies until she became concerned with the breakdown of crystal perfection associated with solid-state reactions.

Another topic she had intended to pursue was the measurement of diamagnetic anisotropy in strained organic molecules, but as many of these were difficult to crystallize, the apparatus was miniaturized and erected on an X-ray camera. This hybrid never functioned satisfactorily, which was unfortunate, because Kathleen was convinced that much of interest could be learned in this way, and she was probably right.

New topics which did get under way arose mainly from her desire to make some contributions in the application of X-ray crystallography to various medical problems. The first of these was the study of $n$ methonium compounds which acted in a similar way to curare, the activity varying with the length of the chain. Although a few of these structures were determined, the results were not really conclusive, and the work was stopped in this laboratory, though it has continued elsewhere. The other project was the study of endemic bladder stones, and this work has continued and expanded over a number of years. During the last wecks of her life, Kathleen Lonsdale worked unremittingly on a book on this subject with the help of one 
of her colleagues, and it is hoped that a version of this text may soon be published.

A wholly different topic to which she returned from time to time, as do so many of those who have ever studied it, was some aspect of research on diamond. In later years she wrote a number of papers on synthetic diamonds, and her contributions to this field were recognized when the wurtzite form of carbon was named lonsdaleite after it had been discovered as a naturally occurring mineral in meteorites.

At University College, Kathleen had many other things to occupy her time. Once persuaded that the luxury of pure research was something of which she should no longer avail herself, she threw herself with her customary energy into the establishment of appropriate courses. She gave a series of university extension lectures which she wrote up as a book entitled Crystals and X-rays (1949), and prepared a large collection of notes and slides intended partly for the intercollegiate M.Sc. course then being run in conjunction with Bernal's department at Birkbeck College (evening students found much of it rather heavy going) and partly for the third-year chemists at University College (who found the going equally heavy).

Kathleen was not really a good teacher in the generally accepted sense of the word. This was not because she failed to prepare adequate material, but simply because she would not accept the fact that all students did not have her intellectual capacity, and that beyond a certain level diligence is not a substitute for ability; she tended to believe that students could master anything if they would only work hard enough, as she herself had always been able to do. She would explain anything to anyone once, but did not expect to have to do so again, although she was extremely patient with foreign students, who were exempt from the normal rule because they were likely to have difficulties with the language. She did, however, take a very active interest in the training of crystallographers, and would have preferred to see crystallography established as a separate discipline just as chemistry or physics are established.

The other major activity with which she was concerned during her time at University College was the preparation of International Tables for X-ray Crystallography, having overall responsibility for the production of the first three volumes. This entailed a prodigious amount of work, which curtailed her own researches to some extent, but she saw this as a contribution to the general good, likely to be at least equally as valuable as an individual contribution to scientific knowledge. She also served the IUCr in other ways. Always careful not to be associated with any organization in which she did not intend to take an active interest, when she became Vice-President of the Union at a time when the President was unwell, and the close proximity of their two laboratories made it easy for her to be in touch with him, she dealt with the minutiae of Union affairs with the same routine attention to detail which usually resulted in the amendment of hitherto unrecognized incompatibilities in the by-laws of any organization of which she became an officer.

This recognition of the responsibility of involvement operated to keep her scientific interests much narrower than might at first sight appear to be the case. She never took the slightest interest in research on defectcontrolled crystal growth, refused the offer of good electron diffraction equipment in return for training students to use it, had no interest in the derivation of atomic scattering factors, potential functions or any of the many types of spectra obtainable from crystals, and made no major contributions to the development of direct methods or other structure-solving techniques. She remained in essence a crystal physicist, and apart from W. H. Bragg, the most important influence on her scientific outlook was probably Michael Faraday. Working in Faraday's room at the Royal Institution, she read his notebooks and absorbed his approach to experimentation. She often reminded me that Faraday had discovered all the important laws governing electromagnetic phenomena accessible with the apparatus available to him without recourse to anything other than simple arithmetic. She was herself a great experimentalist, and in her later years became less and less attracted to complicated mathematical formulations of problems which she felt could be tackled directly from first principles; 'One of us', she wrote at the end of a paper in 1959 'would like here to acknowledge personal indebtedness to the late Sir William Bragg for a training which emphasized that a simple approach to a difficult problem is not necessarily an inaccurate one'.

As such a sentiment implies, she preferred simple apparatus to complicated equipment, and although she had used the original ionization spectrometer, and had been among the earliest users of diffractometers in the U.S.A. when she was a special research fellow at the N. I. H. in Bethesda in 1947, to the end of her life she preferred photographic methods. This was not only because of their inherent simplicity, but also because those phenomena which interested her most gave rise to diffuse scattering, which is notoriously difficult to map with counters having restricted apertures, and because a photograph records the unexpected as well as the expected, whereas a counter only records what occurs at a predetermined position. She was particularly skilled at extracting information from Laue photographs, and frequently deplored the fact that they were becoming increasingly unfamiliar to successive generations of crystallographers brought up on more sophisticated techniques. Much of her own work had been done from stationary-crystal photographs, and she was actively interested in the several methods involving Laue photographs which were developed in her laboratory over the years.

In her 'public' life, Kathleen Lonsdale liked to remind audiences that she had been born in the year in which the Wright brothers first flew an aeroplane, and 
she lived long enough to watch public interest in moon-landings wane. The problems attendant on such spectacular progress in science and technology were among her most constant preoccupations. She was not among those who feel that scientists, by virtue of their special training, are better equipped than others to rule the world, though she often expressed the view that politicians would do well to attempt to quantify their uncertainties as diligently as scientists do. She did, however, feel very strongly that in view of the immense importance and complexity of modern science and technology, scientists do have a special responsibility to try to ensure that science as a whole is rightly used, and hence must involve themselves in enabling the general public to understand enough about science to make informed choices involving scientific judgments.

She was well aware, not least through having spent many years at the Royal Institution, that popularizing science is an extremely arduous and demanding activity, but she found time to prepare many excellent broadcasts, lectures and articles intended for nonspecialist audiences. She also belonged to specialist pressure groups such as the Atomic Scientists Association, attended gatherings such as Pugwash Conferences where the interaction between scientists and governments is most direct, and wrote a Penguin Special entitled Is Peace Possible? (1957) which drew attention to many of the technological considerations involved in international disputes. Throughout her life she had been a fairly regular attender at the Annual Meetings of the British Association for the Advancement of Science, and after serving as one of its General Secretaries from 1960 to 1964, in 1967, in Leeds, where she had first attended a meeting 40 years earlier, she was elected the first woman President of the B. A. She was deeply involved in promoting structural changes in the organization to improve its relevance to and interaction with the community as a whole, and arranging for discussion of controversial issues such as factory farming.

It is my conviction that Kathleen Lonsdale was much beloved by the scientific community in which she worked, not in spite of her personal beliefs, but because of them, although the majority of those with whom she came into contact did not share many of her views. Her exceptional intellect and relentless logic drove her towards practical solutions of problems once she had become involved with them, and her almost infinite capacity for hard work ensured that once a course of action had been determined, progress was steady. She was an active member of the Society of Friends (Quakers), which she joined in 1935; she had faith in certain things, and defined exactly what she meant by faith; faith is a principle on which you base action. It is no use saying that you believe in the friendly treatment of minorities if you habitually bully the office boy, because your actions show that you believe nothing of the kind. She lived rather consistently by a number of such precepts, which she frequently enunciated in lectures and pamphlets. One of those which most influenced her whole life, scientific and otherwise, was scrupulous attention to the evidence and a desire to avoid unwarranted deductions. She illustrated this by the story of the teacher who asked the children in her class what they would think if they went into a room and saw a number of cobwebs in the corners. Various children answered that they would think that the lady of the house was lazy, or unwell, or on holiday, but one child replied: 'I would think that a spider had been there'.

Those accustomed to equate religious convictions with unworldliness often had a rude awakening when dealing with Kathleen, who could be a very tough negotiator, and had always done her homework on the committee papers. 'It's lucky one of us is an idealist' she would remark, while coping expertly with the practical side of some rarified gathering, because she had an unshakeable conviction that the right course of action in any circumstances was by definition also the most practical one. She also had a great sense of humour and a most perceptive appreciation of the best things in life. She concluded her Inaugural Lecture at University College by explaining that crystallographers were, like Walter de la Mare's Wizards 'a flock of crazy prophets who by staring at a crystal can fill it with more wonders than are herrings in the sea'. She did her share.

H. JUdith Milledge 